\title{
High-frequency oscillatory ventilation in a tertiary paediatric intensive care unit in an academic hospital in Johannesburg, South Africa
}

\author{
S Cawood, ${ }^{1}$ MB ChB, DCh, FCPaed, MMed (Paed); Cert Crit Care (Paed) OrcID 0000-0003-2099-8616; \\ B Rae, ${ }^{2} \mathrm{MB}$ ChB; OrcID 0000-0002-3343-4759; \\ K D Naidoo, ${ }^{1}$ MB ChB, DCh, FCPaed, MMed (Paed) Cert Crit Care (Paed); OrcID 0000-0001-5745-4351 \\ ${ }^{1}$ Division of Critical Care, Faculty of Health Sciences, University of Witwatersrand, Johannesburg, South Africa \\ ${ }^{2}$ Division of Emergency Medicine, Faculty of Health Sciences, University of Witwatersrand, Johannesburg, South Africa
}

Correspondingauthor: S Cawood (shancawood@gmail.com)

\begin{abstract}
Background. High-frequency oscillatory ventilation (HFOV) remains an option for the management of critically ill children when conventional mechanical ventilation fails. However, its use is not widespread, and there is wide variability reported with respect to how it is used.

Objectives. To describe the frequency, indications, settings and outcomes of HFOV use among paediatric patients with a primary respiratory disorder admitted to a tertiary paediatric intensive care unit (PICU).

Methods. The study was a 2-year, single-centre, retrospective chart review.

Results. Thirty-four (32.7\%) patients were managed with HFOV in the PICU during the study period. Thirty-three of the 34 patients had paediatric acute respiratory distress syndrome. Indications for HFOV were inadequate oxygenation in 17 patients (50\%), and refractory respiratory acidosis in 15 patients (44.1\%) (2 patients did not fit into either category). Approaches to the setting of HFOV varied considerably, particularly with respect to initial pressure around the airways. HFOV was effective at improving both oxygenation, with a median (interquartile range (IQR)) decrease in oxygenation index of 6.34 (5.0 - 9.5), and ventilation with a the median decrease in PaCO2 of 67.6 (46.2 - 105.7) mmHg after 24 hours. Overall mortality was $29.4 \%$ in the HFOV group, which is consistent with other studies.

Conclusion. HFOV remains an effective rescue ventilatory strategy, which resulted in rapid and sustained improvement in gas exchange in patients with severe hypoxaemia and/or severe respiratory acidosis, particularly in the absence of extracorporeal support. However, the variability in practice and the adverse effects described highlight the need for future high-quality randomised controlled trials to allow for development of meaningful guidelines to optimise HFOV use.

Keywords. Mechanical ventilation, high frequency oscillatory ventilation, paediatric acute respiratory distress syndrome, oxygenation index, paediatric intensive care unit.
\end{abstract}

South Afr J Crit Care 2019;35(2):56-61. https://doi.org/10.7196/SAJCC.2019.v35i2.396

\section{Contribution of study}

This study describes the use and outcomes of high-frequency oscillatory ventilation (HFOV) in a South African paediatric intensive care unit, thus addressing a local knowledge gap and providing evidence of the continued efficacy of HFOV for severe hypoxaemia and refractory respiratory acidosis in settings without access to extracorporeal technologies.

Conventional mechanical ventilation (CMV) is sometimes unable to achieve adequate gas exchange, necessitating the use of nonconventional ventilatory strategies. The recent Pediatric Acute Lung Injury Consensus Conference (PALICC) recommended the use of high frequency oscillatory ventilation (HFOV) in severe paediatric acute respiratory distress syndrome (PARDS) as an alternative (or rescue) ventilatory mode. ${ }^{[1]}$ Reported use of HFOV in critically ill children varies between $3 \%$ and $30 \% \cdot{ }^{[2-4]}$ Despite the putative benefits of HFOV, randomised controlled trials in paediatrics demonstrating the superiority of HFOV over conventional modes are scarce, so the role of HFOV remains confined to use as salvage within recent paediatric mechanical ventilation guidelines. ${ }^{[1,5]}$ HFOV has come under scrutiny with the recent publication of two large trials looking at HFOV in adults with moderate to severe acute respiratory distress syndrome. The lack of benefit found, as well as concerns regarding potential harm, have prompted deliberations around its continued use. ${ }^{[6,7]}$

Practices around HFOV use vary, and may need to be refined. ${ }^{[4]}$ HFOV has generally been considered a rescue strategy, and as such, the optimum timing of initiation is unclear. ${ }^{[8,9]}$ The most commonly used triggers to transition from $\mathrm{CMV}$ to HFOV are both markers of oxygenation, namely the $\mathrm{PaO}_{2}: \mathrm{FiO}_{2}(\mathrm{PF})$ ratio and the oxygenation index (OI); however, a wide range of values for both parameters has been reported. ${ }^{[10-14]}$ Generally, HFOV is suggested when oxygenation remains severely impaired $\left(\mathrm{SpO}_{2}<88 \%\right.$ and/or $\mathrm{PaO}_{2}<50 \mathrm{mmHg}$ with a $\left.\mathrm{FiO}_{2}>0.6\right)$ despite maximal lung-protective $\mathrm{CMV}$ limiting peak pressures to less than $30-35 \mathrm{cmH} 20$ with sufficient positive end-expiratory pressure 
(PEEP). ${ }^{[2,4,10,15]}$ An OI $\geq 13$ on two blood gases 6 hours apart has been recommended as a trigger for transition to HFOV, though the optimal OI threshold remains unclear. ${ }^{[4,10]}$ Additionally, some recommendations suggest the use of HFOV for refractory respiratory acidosis using a $\mathrm{PaCO}_{2} \geq 80 \mathrm{mmHg}$ or a $\mathrm{pH} \leq 7.25$ as trigger criteria. ${ }^{[2,3,16]}$

The initial settings of the HFOV have, perhaps unsurprisingly, varied considerably between reports. Airway pressure (Paw) has been set at varying levels relative to the mean airway pressure produced by CMV (cMAP), with some suggesting setting Paw at the same level as cMAP, ${ }^{[2]}$ while others suggest anywhere up to $8 \mathrm{cmH}_{2} 0$ above cMAP. ${ }^{[10-12,17]}$ Paw has then been titrated based on oxygenation and chest inflation on radiograph. ${ }^{[2-4,10,12,14,18,19]}$ The initial frequency has been guided by the age and weight of the patient, with values ranging between 5 and $10 \mathrm{~Hz}$ for patients weighing $\geq 10 \mathrm{~kg}$, and 10 and $15 \mathrm{~Hz}$ for patients weighing $<10 \mathrm{~kg}$. ${ }^{[2-4,8,10,11,17,18,20]}$ Strategies to set amplitude have used 'chest wall wiggle, with subsequent titration, together with frequency if required, to achieve a $\mathrm{PaCO}_{2}$ target. ${ }^{[2,10-12,14,18]}$ Reported triggers prompting transition back to CMV have also varied widely, with the use of objective criteria for Paw $\left(10-20 \mathrm{cmH}_{2} \mathrm{O}\right)$ and $\mathrm{FiO}_{2}(\leq 0.5)$, as well as the more subjective criterion of absence of significant desaturation with suctioning. ${ }^{[1,12,18,20]}$

Two years' experience in managing paediatric patients with respiratory failure using HFOV in a tertiary paediatric intensive care unit (PICU) is presented in the present study. The objectives were to describe the population of patients in which HFOV was used, the triggers used for initiation of and transitioning from HFOV and the initial settings of HFOV. Further objectives were to describe the response of patients, the incidence of complications and the short-term outcomes.

\section{Methods}

This retrospective chart review was carried out in the PICU at the Chris Hani Baragwanath Academic Hospital in Soweto in Johannesburg, South Africa (SA), from 1 October 2014 to 30 September 2016. Patients $<16$ years old with respiratory conditions who required HFOV (SensorMedics 3100B) were identified using the ICU database. Data collected included baseline characteristics, ventilator settings and outcomes, which were collated using Excel software (Microsoft, USA). Baseline characteristics included age, admission weight, diagnosis and parameters required to calculate the paediatric index of mortality 3 (PIM3) score. Data regarding ventilation included the settings on CMV just prior to transitioning to HFOV, settings once on HFOV $\left(\mathrm{HFOV}_{\mathrm{i}}\right)$, and after 24 hours on HFOV $\left(\mathrm{HFOV}_{24}\right)$. Outcomes data included the response of patients' oxygenation and ventilation parameters to HFOV, using measured blood gas parameters as well as calculated PF ratios and OI. The severity of PARDS was defined according to the PALICC recommendations (Table 1). PF ratio $\leq 300$ and OI $\geq 4$ were used to define hypoxaemic respiratory failure. Respiratory acidosis was defined as $\mathrm{PaCO}_{2} \geq 60 \mathrm{mmHg}$ and $\mathrm{pH} \leq 7.25$. $^{[16]}$ Further outcome data collected included in-ICU mortality, duration of mechanical ventilation, ICU length of stay, presence of pneumothorax and new or increasing need for vasoactive agents. The research was approved by the Human Research Ethics Committee of the Faculty of Health Sciences of the University of the Witwatersrand (ref. no. M161176).

Patients' data were placed into two groups. Group A were patients transitioned for inadequate oxygenation where a cut-off of $\mathrm{OI} \geq 12$ was used, as per unit guidelines. Group B were patients transitioned for severe respiratory acidosis $\left(\mathrm{PaCO}_{2} \geq 60 \mathrm{mmHg}\right.$ and $\left.\mathrm{pH} \leq 7.25\right) .{ }^{[16]}$

Descriptive statistics were used to report the data. Categorical variables were described using frequencies and percentages. Continuous variables were described using medians and interquartile ranges (IQRs),
Table 1. PALICC recommendations on PARDS severity ${ }^{[1]}$

\begin{tabular}{llll}
\hline & Mild PARDS & Moderate PARDS & Severe PARDS \\
\hline OI $^{*}$ & $4-<8$ & $8-<16$ & $\geq 16$ \\
OSI $^{\dagger}$ & $5-<7.5$ & $7.5-<12.3$ & $\geq 12.3$
\end{tabular}

PALICC $=$ Pediatric Acute Lung Injury Consensus Conference; PARDS = paediatric acute respiratory distress syndrome; $\mathrm{OI}=$ oxygenation index, $\mathrm{OSI}=$ oxygen saturation index. ${ }^{*} \mathrm{OI}$ was calculated as $\left(\left(\right.\right.$ mean airway pressure $\left.\left.\mathrm{FiO}_{2}\right) / \mathrm{PaO}_{2}\right) \times 100$. When ventilatory data were not available to calculate an $\mathrm{OI}, \mathrm{PF}$ or $\mathrm{SF}$ ratios were calculated. $\mathrm{PF}$ ratios were calculated as $\left(\mathrm{PaO}_{2} / \mathrm{FiO}_{2}\right)$, and $\mathrm{SF}$ ratios were calculated as $\left(\mathrm{SpO}_{2} / \mathrm{FiO}_{2}\right)\left(\right.$ with $\left.\mathrm{SpO}_{2} 92-97 \%\right)$ When an arterial blood gas measurement was not available, $\mathrm{SpO}_{2}$ was used to calculate an OSI, with OSI $=\left(\left(\mathrm{FiO}_{2} \times\right.\right.$ mean airway pressure $\left.) / \mathrm{SpO}_{2}\right) \times 100\left(\right.$ with $\left.\mathrm{SpO}_{2} 92-97 \%\right)$

as the data were not normally distributed. Calculations were performed using Statistica version 13.05.0.17 (TIBCO Software Inc., USA).

\section{Results}

During the study period, 687 paediatric patients were admitted to the PICU, with 104 (15.1\%) admitted with primarily respiratory conditions. Thirty-four $(32.7 \%)$ of these patients were managed with HFOV. All patients with sufficient data to calculate OI $(n=31 ; 91.2 \%)$ fulfilled the diagnostic criteria for PARDS just prior to the transition to HFOV. Two of the remaining patients had either a PF or SF ratio consistent with hypoxaemic respiratory failure, while there were no blood gas data for the other patient to calculate any indices.

\section{Transitioning to HFOV}

Twenty-six patients (76.5\%) were transitioned to HFOV within 24 hours of admission. Of the remaining 8 patients, $6(17.7 \%)$ were transitioned within 72 hours, and 2 were transitioned on days 4 and 5, respectively. Seventeen patients $(50.0 \%)$ were transitioned for inadequate oxygenation (Group A). Fifteen (44.1\%) were transitioned for severe respiratory acidosis (Group B). In Group B, 8 patients also displayed significant oxygenation defects, with a median (IQR) OI of 26.5 (17.1 - 30.5). Two patients did not meet the criteria for classification into either group. Table 2 further outlines the characteristics of the two groups.

The PEEP/ $/ \mathrm{FiO}_{2}$ combinations and resultant OIs of each patient in Group A prior to the transition to HFOV are illustrated in Fig. 1. PEEP data were missing for 2 patients.

In Group B, the median (IQR) $\mathrm{PaCO}_{2}$ was 122.0 (84.9.0 - 171.8), $\mathrm{mmHg}$ and the median (IQR) $\mathrm{pH}$ was $6.92(6.84-7.01)$, with a median (IQR) minute ventilation of $0.35(0.28-0.42) \mathrm{L} / \mathrm{kg} / \mathrm{min}$. This median minute ventilation is $72.9 \%$ of the upper limit of normal for the infant (normal range $0.24-0.48 \mathrm{~L} / \mathrm{kg} / \mathrm{min}$ ), and all patients in this group were between the ages of 1 and 5 months.

\section{Initial and 24-hour HFOV settings, and response of oxygenation and ventilation parameters}

In Group A, settings on $\mathrm{CMV}, \mathrm{HFOV}_{\mathrm{i}}$ and $\mathrm{HFOV}_{24}$, as well as the response of oxygenation parameters, are illustrated in Fig. 2. Increases in Paw varied, with a median (IQR) increase of $7(4-10) \mathrm{cmH}_{2} 0$ above cMAP. Four (23.5\%) patients were transitioned to a $\mathrm{Paw}<4 \mathrm{cmH}_{2} 0$ above cMAP; 3 (17.6\%) were transitioned with a Paw $4-6 \mathrm{cmH}_{2} 0$ higher than CMAP; and 7 (41.2\%) were transitioned to a Paw $>6 \mathrm{cmH}_{2} 0$ higher than cMAP. Data on Paw were missing for 3 patients. Median (IQR) amplitude was $44(40-51) \mathrm{cmH}_{2} 0$, and median (IQR) frequency was 10 $(8-10) \mathrm{Hz}$, which remained relatively unchanged at 24 hours. $\mathrm{PaCO}_{2}$ also showed improvement on HFOV with a median (IQR) $\mathrm{PaCO}_{2}$ of 47.3 (36.7 - 57.9) $\mathrm{mmHg}, 44.6$ (36.2 - 52.0) $\mathrm{mmHg}$ and 42.6 (35.5 - 47.8) $\mathrm{mmHg}$ on $\mathrm{CMV}, \mathrm{HFOV}_{\mathrm{i}}$ and $\mathrm{HFOV}_{24}$, respectively. 


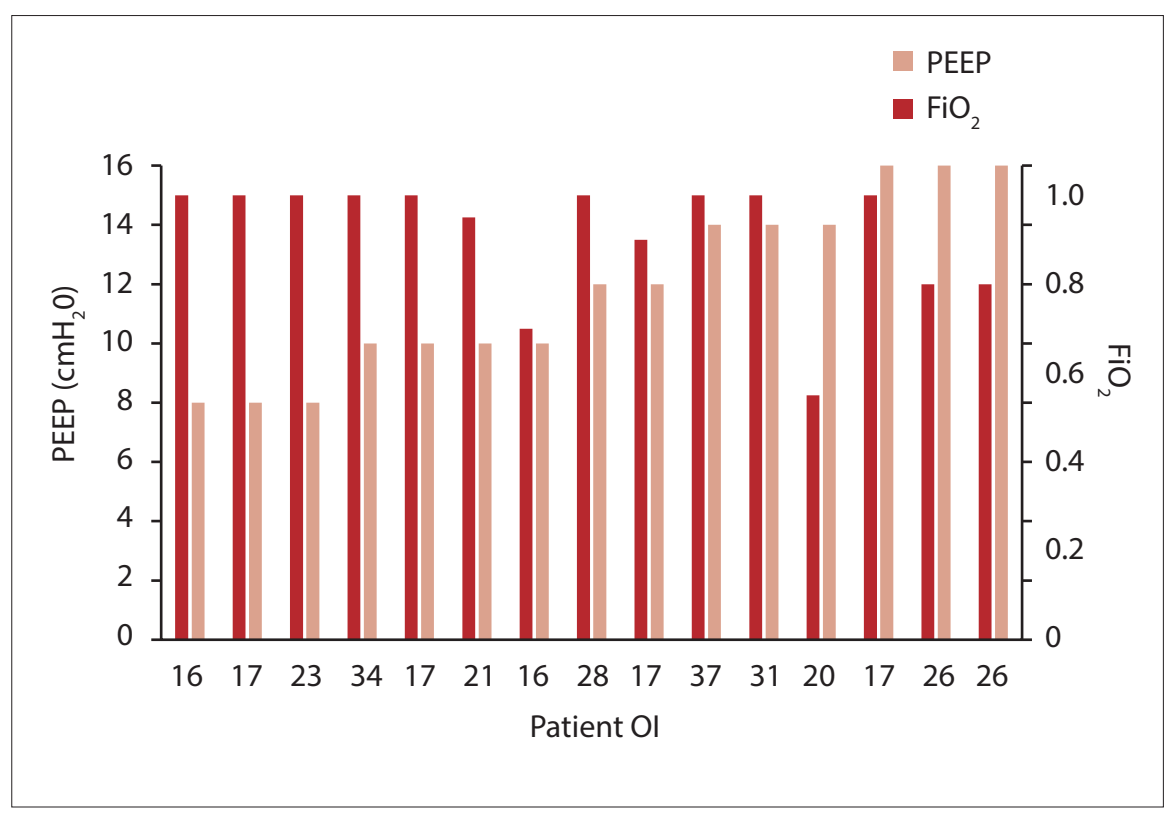

Fig. 1. PEEP/FiO ${ }_{2}$ values for patients in Group A ( $n=15$; data missing for 2 patients). ( $P E E P=$ positive endexpiratory pressure; $\mathrm{OI}=$ oxygenation index.)

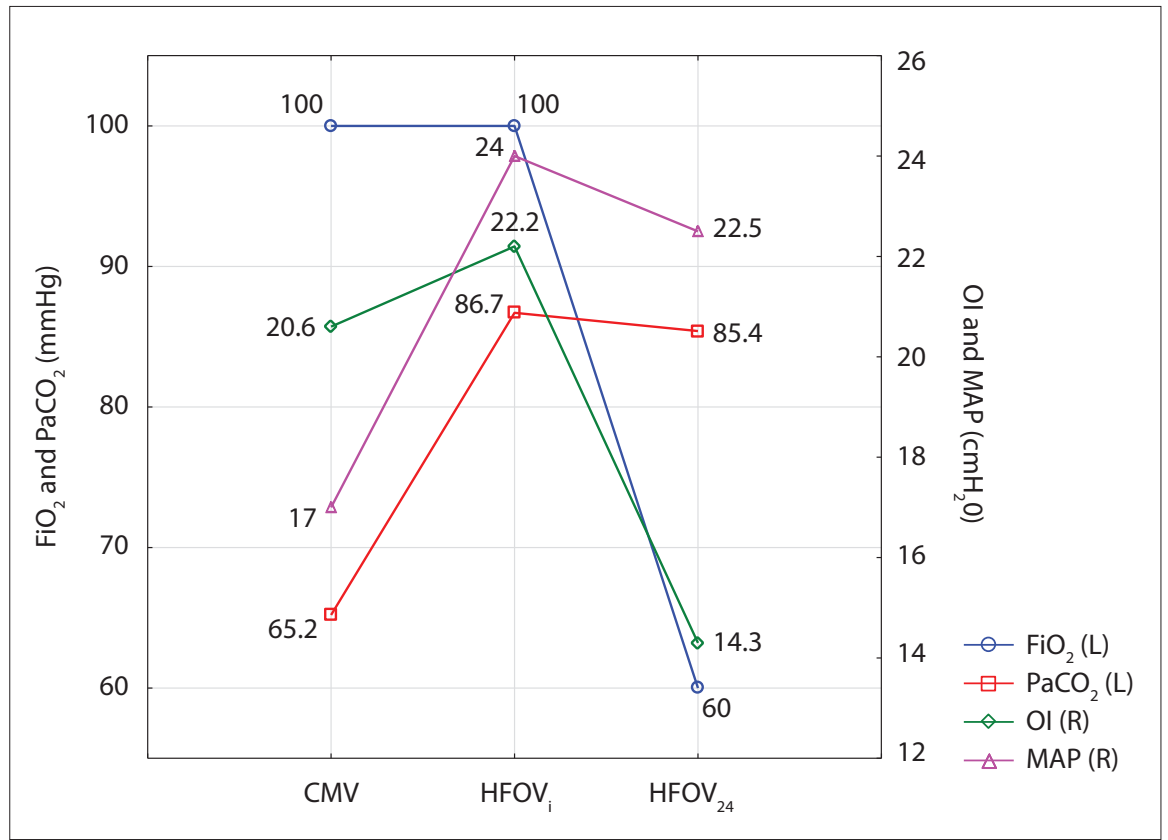

Fig. 2. Settings and oxygenation parameters on $\mathrm{CMV}, \mathrm{HFOV}_{i}$ and $\mathrm{HFOV}_{24}$ in Group A ( $\left.n=17\right)$.

$\left(C M V=\right.$ conventional mechanical ventilation; $H F O V=$ high-frequency oscillatory ventilation; $H F O V_{i}=$ initial HFOV settings, $H_{F O V_{24}}=H F O V$ settings after 24 hours; $O I=$ oxygenation index; $M A P=$ mean airway pressure; $L=$ Left; $R=$ Right.)

In Group B, patients were transitioned to a median (IQR) $\mathrm{FiO}_{2}$ of $1.0(0.8-1.0)$, and a median (IQR) Paw of $23(21-25) \mathrm{cmH}_{2}$. Median (IQR) amplitude was 44 (39 - 49) $\mathrm{cmH}_{2} 0$, and median (IQR) frequency was $8(8-10) \mathrm{Hz}$. Changes in $\mathrm{PaCO}_{2}$ and $\mathrm{pH}$ on $\mathrm{CMV}, \mathrm{HFOV}_{4}$ and $\mathrm{HFOV}_{24}$ are illustrated in Table 3. At 24 hours, the median (IQR) frequency had increased to $9(8-10) \mathrm{Hz}$, while amplitude was relatively unchanged at a median (IQR) of $42(40-45) \mathrm{cmH}_{2} 0$.

\section{Triggers for transitioning to CMV}

All patients were transitioned with an $\mathrm{FiO}_{2}$ $\leq 0.6$, with the majority $(64 \%)$ at an $\mathrm{FiO}_{2} \leq 0.4$. Most patients (86.9\%) were transitioned with a cMAP $\leq 20 \mathrm{cmH}_{2} 0$. Twenty patients $(80.0 \%)$ were transitioned with an $\mathrm{OI} \leq 13$. Three patients (12.0\%) were transitioned with an OI 14 - 17. Data on triggers for transitioning to CMV was missing for the remaining 2 of the 25 patients who were transitioned to CMV.

\section{Outcomes}

The survival rate for patients who were treated with HFOV was $70.6 \%$. Eight $(80.0 \%)$ mortalities occurred in the severe PARDS group, with 2 occurring in the moderate PARDS group. Mortality was higher than that predicted by the PIM3, with a mortality rate of $28.6 \%$ v. the $5.9 \%$ predicted in the moderate PARDS group and $34.8 \% \mathrm{v}$. the $9.5 \%$ predicted in the severe PARDS group. The median (IQR) duration of mechanical ventilation was $9(8-10), 12(8-22)$ and $11(8-13)$ days in the mild, moderate and severe PARDS groups, respectively. The median (IQR) PICU lengths of stay were $10(9-12), 13(11-24)$ and 12 (9 - 14) days in the mild, moderate and severe PARDS groups, respectively.

\section{Adverse events}

Nineteen $(55.9 \%)$ patients required new or increasing vasoactive support 4 hours after initiation of HFOV, with this occurring in $20.0 \%$ of patients who were transitioned to a Paw $<4 \mathrm{cmH}_{2} \mathrm{O}$ above cMAP, in $55.6 \%$ of patients who were transitioned to a Paw $4-6 \mathrm{cmH}_{2} \mathrm{O}$ above cMAP and in $80.0 \%$ of patients who were transitioned to a Paw $>6 \mathrm{cmH}_{2} 0$ above cMAP. Four (11.8\%) patients developed pneumothoraces.

\section{Discussion}

HFOV has been proposed as a ventilator strategy for paediatric patients when CMV fails to achieve adequate gas exchange. However, the literature on the topic is limited, and evidence supporting the utility of HFOV remains elusive. The present study aimed to describe the clinical application of HFOV in our paediatric population, and evaluate our patients' response to its use.

During the study period, a substantial proportion (32.7\%) of patients with respiratory conditions were managed with HFOV, slightly higher than the reported use of HFOV globally, of between 3 and 30\%.2-4] The use of HFOV is usually in the setting of hypoxaemic respiratory failure necessitating ventilator settings in excess of accepted safe limits, or failure to achieve adequate gas exchange using CMV, particularly in units without access to extracorporeal respiratory support, as is the case in the study PICU. ${ }^{[1,8,10,11,17]}$ While 25 (73.5\%) of the patients included in the study did indeed meet unit criteria for transition to HFOV on the basis of oxygenation criteria $(\mathrm{OI} \geq 12)$, somewhat surprisingly, nearly half (44.1\%) of the indications for HFOV were refractory respiratory acidosis. 
Table 2. Patient characteristics $(N=34)$

\begin{tabular}{|c|c|c|c|}
\hline Variable & All $^{*}$ & Group A $(n=17)^{*}$ & Group B $(n=15)^{*}$ \\
\hline Age (months), median (IQR) & $2.75(2.0-3.75)$ & $3.0(2.0-5.0)$ & $2.0(2.0-3.0)$ \\
\hline Weight $(\mathrm{kg})$, median (IQR) & $4.5(3.93-5.48)$ & $4.5(4.5-5.95)$ & $4.5(3.8-4.9)$ \\
\hline \multicolumn{4}{|l|}{ Age (months), $n$ (\%) } \\
\hline $1-3$ & $25(73.5)$ & $10(58.8)$ & $13(86.7)$ \\
\hline$>3-6$ & $6(17.7)$ & $4(23.5)$ & $2(13.3)$ \\
\hline$>6-12$ & $1(2.9)$ & $1(5.9)$ & $0(0)$ \\
\hline$>12-24$ & $2(5.9)$ & $2(11.8)$ & $0(0)$ \\
\hline \multicolumn{4}{|l|}{ Diagnosis, $n(\%)$} \\
\hline Bronchopneumonia & $23(67.7)$ & $11(64.6)$ & $11(73.4)$ \\
\hline Bronchiolitis & $3(8.8)$ & $1(5.9)$ & $2(13.3)$ \\
\hline Aspiration pneumonia & $1(2.9)$ & $1(5.9)$ & $0(0.0)$ \\
\hline Pneumocystis pneumonia & $5(14.7)$ & $2(11.8)$ & $2(13.3)$ \\
\hline Chemical pneumonitis & $2(5.9)$ & $2(11.8)$ & $0(0.0)$ \\
\hline PIM3 score, ${ }^{\dagger}$ median (IQR) & $-4.89(-5.10--4.54)$ & $-4.63(-5.03--4.37)$ & $-5.03(-5.11--4.76)$ \\
\hline Probability of mortality (\%), ${ }^{\dagger}$ median (IQR) & $7.6(6.1-10.8)$ & $9.9(6.7-12.9)$ & $6.6(6.1-8.7)$ \\
\hline OI, median (IQR) & $17.4(12.1-25.9)$ & $20.6(17.3-26.9)$ & $14.9(10.3-27.4)$ \\
\hline $\mathrm{PaCO}_{2}(\mathrm{mmHg})$, median (IQR) & $68.9(45.8-101.8)$ & $47.3(36.7-57.9)$ & $122.0(84.9-171.8)$ \\
\hline \multicolumn{4}{|l|}{ PARDS severity, $n(\%)$} \\
\hline Mild & $2(5.9)$ & $0(0.0)$ & $2(13.3)$ \\
\hline Moderate & $9(26.5)$ & $0(0.0)$ & $7(46.7)$ \\
\hline Severe & $23(67.6)$ & $17(100.0)$ & $6(40.0)$ \\
\hline
\end{tabular}

Table 3. Ventilatory parameters on $\mathrm{CMV}, \mathrm{HFOV}_{\mathrm{i}}$ and $\mathrm{HFOV}_{24}$ in group $\mathrm{B}(n=15)$, median (IQR)

\begin{tabular}{llll}
\hline Parameter & CMV & HFOV $_{\mathbf{i}}$ & HFOV $_{24}$ \\
\hline $\mathrm{PaCO}_{2}(\mathrm{mmHg})$ & $112.0(83.3-159.0)$ & $52.9(47.9-67.6)$ & $44.0(37.1-53.3)$ \\
$\mathrm{pH}$ & $6.93(6.85-7.04)$ & $7.28(7.14-7.32)$ & $7.39(7.32-7.44)$
\end{tabular}

$\mathrm{IQR}=$ interquartile range; $\mathrm{CMV}=$ conventional mechanical ventilation; $\mathrm{HFOV}=$ high-frequency oscillatory ventilation; $\mathrm{HFOV}_{\mathrm{i}}=$ initial $\mathrm{HFOV}$ settings, $\mathrm{HFOV}{ }_{24}=\mathrm{HFOV}$ settings after 24 hours.

Among the patients in group A, the ventilatory settings on CMV demonstrated a range of $\mathrm{FiO}_{2}$ and PEEP combinations, with a wide range of resultant OIs. The majority of patients $(80.0 \%)$ had PEEP levels of $10-16 \mathrm{cmH}_{2} \mathrm{O}$ (largely consistent with recent consensus guidelines for severe PARDS), ${ }_{1}^{[1]}$ but 3 patients had a PEEP of $8 \mathrm{cmH}_{2} \mathrm{O}$ and a $\mathrm{FiO}_{2}$ of 1.0 , which produced OIs of 16,17 and 23 , respectively. Indeed, the data did not show a linear relationship between PEEP and $\mathrm{FiO}_{2}$ settings, as might be extrapolated from the adult ARDSNet PEEP:FiO ${ }_{2}$ tables. ${ }^{[21]}$ Therefore, the use of the OI may be refined by the consideration of $\mathrm{FiO}_{2}$ settings together with PEEP in patients with PARDS. Additionally, the fact that virtually all patients with inadequate oxygenation were transitioned to HFOV with an OI in keeping with severe PARDS perhaps suggests that an $\mathrm{OI} \geq 16$ may be a more appropriate trigger to consider the use of HFOV as a rescue therapy, thereby representing a reasonable trade-off between purported benefits and risks. This contrasts with the recent OSCILLATE study, ${ }^{[6]}$ which examined the use of HFOV as a primary ventilatory mode. However, the fact that $76.5 \%$ of patients were transitioned within 24 hours of admission suggests that many of the patients presented at the study site late.

The approach to the setting of HFOV has shown wide variability worldwide. ${ }^{[2,10-12,17]}$ This, taken together with the uncertainty in optimal timing of initiation, has been postulated as the reason for worse outcomes with longer duration of mechanical ventilation, and longer time to lung recovery. ${ }^{[13]}$ Variability was evident in our unit as well, but largely limited to the initial Paw setting. The median (IQR) change in mean airway pressure from CMV to HFOV was $7(4-10) \mathrm{cmH}_{2} 0$, slightly higher than the range most often recommended. ${ }^{[2,10-12,17]}$ The settings of both amplitude and frequency were much more consistent among our study patients.

In Group A, the HFOV settings produced an increase in Paw and OI, but resulted in an increase in $\mathrm{PaO}_{2} 60$ minutes post initiation of HFOV. By 24 hours, the $\mathrm{PaO}_{2}$ was still increasing, but this was now accompanied by a substantial reduction in OI, perhaps adding weight to the calls for prognostication of PARDS patients at 24 hours post admission, rather than on admission. ${ }^{[2,12,13,16-18,22,23]}$

In Group B, the efficacy of HFOV in enhancing ventilation was substantial, with reductions in $\mathrm{PaCO}_{2}$ producing a median $\mathrm{pH}$ of more than 7.25 at 60 minutes. The approach to setting amplitude was the same as that in Group A, but the initial frequency was set $2 \mathrm{~Hz}$ lower, to facilitate $\mathrm{CO}_{2}$ elimination. The amplitudes employed were generally ranges suggested in the majority of the literature, ${ }^{[8,9,16,24]}$ with the exception of a recently proposed physiological, individualised approach to the setting of HFOV that utilised amplitudes of $70-90 \mathrm{cmH}_{2} 0{ }^{[25]}$ The unusually high rate of refractory respiratory acidosis may have been due to the lack of proximal flow sensor utilisation in very young patients with relatively small tidal volumes. Therefore, the frequency with which we use HFOV in this setting may be exaggerated, and could potentially be reduced with more accurate minute ventilation monitoring. Nevertheless, HFOV proved highly effective at improving the removal of $\mathrm{CO}_{2}$ in this group of patients. 
Despite the clear distinction in the indications for the initiation of HFOV, both groups of patients had similar HFOV settings prior to transition back to CMV. Studies have used various combinations of Paw and $\mathrm{FiO}_{2}$ and/or amplitude to trigger transition to $\mathrm{CMV} \cdot{ }^{[3,8,10,12,14,18]} \mathrm{All}$ study patients in this cohort were transitioned with an $\mathrm{FiO}_{2}<0.6(64 \%$ with an $\mathrm{FiO}_{2}<0.4$ ) and $84 \%$ with a Paw $\leq 20 \mathrm{cmH}_{2} \mathrm{O}$. Given the use of OI $>12$ as a trigger to initiate HFOV in the study, it is noteworthy that most patients $(82.6 \%)$ were transitioned with an OI of $\leq 12$.

Complications associated with the use of HFOV appear to be infrequent. ${ }^{[2,3,8,11,12,22]}$ The most common complications reported have been haemodynamic instability requiring vasoactive support, and pneumothoraces. ${ }^{[2,3,8,11,12,22]}$ In our cohort, $55.9 \%$ of patients required either new or increased doses of vasoactive agents within 4 hours of initiation of HFOV. This proportion is in excess of reports from previous HFOV studies. . $^{[3,8,17,20,24]}$ This appeared to be dose-dependent, as vasoactive usage was related to the magnitude of increase in Paw relative to cMAP, evidenced by the $80 \%$ of patients with an initial Paw increase of $>6 \mathrm{cmH}_{2} 0$ who required new or increasing doses of vasoactives. A possible explanation for the difference in haemodynamic stability might be the recent trend toward more fluid-restrictive management of respiratory patients, which may have resulted in reduced preload in the face of increased intrathoracic pressure. ${ }^{[1]}$ The rate of escalation of initial Paw on HFOV may also have relevance, given the lower incidence of haemodynamic instability in a recent feasibility study, where Paw was increased gradually using the researchers' individualised approach, despite final magnitudes of Paw change occurring that were similar to those in the present study. ${ }^{[25]}$

The incidence of pneumothoraces was also higher (11.8\%) than in recent reported studies. ${ }^{[3,8,12,18,22]}$ Of note was the fact that three of the four patients with pneumothoraces were exposed to a substantial increase in Paw of $8-10 \mathrm{cmH}_{2} \mathrm{O}$ when transitioned to HFOV. Given the absence of pneumothoraces in the individualised feasibility study, ${ }^{[25]}$ this again raises the question of the potential protective effect of a gradual increase in Paw, rather than a single large increment. Taken together, the increased vasoactive use and pneumothorax incidence suggest that excessive increases in Paw relative to cMAP may potentially be harmful, and should possibly be limited to $4-6 \mathrm{cmH}_{2} \mathrm{O}$ on initiation of HFOV.

Mortality in patients with PARDS has been reported at anywhere between 10 and $40 \%$ overall, and $13-42 \%$ in those managed with HFOV ${ }^{[12,17]}$ The overall mortality of $29.4 \%$ in our study is therefore in line with international norms. ${ }^{[12,17]}$ However, particularly with respect to the patients with severe PARDS, the observed mortality was $34.8 \%$, while the PIM3 predicted mortality was $9.5 \%$. Given that the most severe patients had observed mortality consistent with previous studies, yet so much in excess of the PIM3 estimation, this calls into question the applicability of the PIM3 to this particular group of critically ill children.

To the best of our knowledge, ours is the first study to describe the use and outcomes of HFOV in an SA PICU, thus addressing a local knowledge gap. It has highlighted the efficacy of the modality for both severe hypoxaemia and respiratory acidosis, while simultaneously revealing wide variation in the approach to the setting of HFOV, which may have directly contributed to the above-average reported adverse effects.

The role of HFOV as a successful option for rescue suggested in the present study is perhaps contradicted by a recent propensity analysis ${ }^{[13]}$ comparing early HFOV with CMV/late HFOV, which found that early use of HFOV was associated with longer durations of mechanical ventilation, after adjusting for baseline differences, including severity of illness. While we did not compare the outcomes of early HFOV to CMV/ late HFOV within our cohort, it is clear that prospective randomised trials are needed to clarify the role of HFOV and the optimal timing of transition both to and from HFOV.

\section{Limitations}

This study was conducted at a single unit where HFOV is utilised as a rescue modality, thus producing a relatively small sample size during the study period. This limits the generalisability of our results to other PICUs. In addition, the retrospective methodology of the study relied on the accuracy of record keeping.

\section{Conclusion}

HFOV was applied to nearly one-third of patients with acute respiratory failure. It was an effective rescue ventilatory strategy that resulted in rapid and sustained improvement in gas exchange in patients with severe hypoxaemia and/or severe respiratory acidosis where CMV settings had approached limits of safe use, and in the absence of extracorporeal support. However, the variability of practice, and the adverse events described, highlight the need for future high-quality randomised controlled trials to explore the most efficient timing $(\mathrm{OI} \geq 16)$ and subsequent settings (initial increase in Paw $\left.4-6 \mathrm{cmH}_{2} 0\right)$ of HFOV. This would allow for the development of meaningful guidelines to optimise future HFOV use.

Acknowledgements. We acknowledge the contribution of Juan Scribante and Francesca Rubulotta in editing the manuscript.

Author contributions. BR and $\mathrm{KDN}$ both contributed to the design of the study, with BR completing the data collection. SC and KDN contributed to the data analysis and final manuscript preparation. Funding. None.

Conflicts of interest. None.

1. Pediatric Acute Lung Injury Consensus Conference Group. Paediatric acute respiratory distress syndrome: Consensus recommendations from the Pediatric Acute Lung Injury Consensus syndrome: Consensus recommendations from the Pediatric Acute Lung Injury Consensus
Conference. Pediatr Crit Care Med J 2015;16(5):428-439. https://doi.org/10.1002\%2Fppul.22853

2. Yehya N, Topjian AA, Lin R, Berg RA, Thomas NJ, Friess SH. High-frequency oscillation and airway pressure release ventilation in pediatric respiratory failure. Pediatr Pulmono 2014;49(7):707-715. https://doi.org/10.1002\%2Fppul.22853

3. Yildizdas D, Yapicioglu H, Bayram I, Yilmaz L, Sertdemir Y. High-frequency oscillatory ventilation for acute respiratory distress syndrome. Indian J Pediatr 2009;76(9):921-927.

4. Kneyber MCJ, van Heerde M, Markhorst DG. Reflections on pediatric high-frequency oscillatory ventilation from a physiologic perspective. Respir Car 2012;57(9):1496-1504. https://doi. org/10.4187/respcare.01571

5. De Luca D, Calderini E, Jarreau P-H, Javouhey E, et al. Recommendations for mechanical Conference (PEMVECC). Intensive Care Med 2017;43(12):1764-1780. https://doi.org/10.1007 s00134-017-4920-z

6. Ferguson ND, Cook DJ, Guyatt GH, et al. High-frequency oscillation in early acute respiratory distress syndrome. N Engl J Med 2013;28;368(9):795-805. https://doi.org/10.1056/ NEJMoa1215554

7. Young D, Lamb SE, Shah S, et al. High-frequency oscillation for acute respiratory distress syndrome. N Engl J Med 2013 28;368(9):806-13. https://doi.org/10.1056/NEJMoa1215716

8. Ben Jaballah N, Mnif K, Bouziri A, Kazdaghli K, Belhadj S, Zouari B. High-frequency oscillatory ventilation in paediatric patients with acute respiratory distress syndrome? Early rescue use. Eur J Pediatr 2005;164(1):17-21.

9. Rettig JS, Smallwood CD, Walsh BK, et al. High-frequency oscillatory ventilation in pediatric acute lung injury: A multicentre international experience. Crit Care Med 2015;43(12):2660-2667. https://doi.org/10.1097/CCM.0000000000001278

10. Hamel DS, Cheifetz IM. High-frequency oscillatory ventilation - a clinical approach. South Afr J Crit Care 2005;1;21(1):15-24.

11. Slee-Wijffels FY, van der Vaart KR, Twisk JW, Markhorst DG, Plötz FB. High-frequency oscillatory ventilation in children - a single-centre experience. Crit Care 2005;9(3):R274.

12. Babbitt CJ, Cooper MC, Nussbaum E, Liao E, Levine GK, Randhawa IS. High-frequency oscillatory ventilation in pediatric acute hypoxemic respiratory failure: Disease-specific morbidity survival analysis. Lung 2012;190(6):685-690. https://doi.org/10.1007/s00408-012-9417-5

13. Bateman ST, Borasino S, Asaro LA, et al. Early high-frequency oscillatory ventilation in pediatric acute respiratory failure. A propensity score analysis. Am J Respir Crit Care Med 2016;193(5):495503. https://doi.org/10.1164/rccm.201507-1381OC

14. Fedora M, Klimovic M, Seda M, Dominik P, Nekvasil R. Effect of early intervention of highfrequency oscillatory ventilation on the outcome in pediatric acute respiratory distress syndrome. Bratisl Lek Listy 2000;101(1):8-13.

15. Froese AB, Kinsella JP. High-frequency oscillatory ventilation: Lessons from the neonatal/ pediatric experience. Crit Care Med 2005;33(Suppl):S115-S121. 
16. Sarnaik AP, Meert KL, Pappas MD, Simpson PM, Lieh-Lai MW, Heidemann SM. Predicting outcome in children with severe acute respiratory failure treated with high-frequency ventilation. Crit Care Med 1996;24(8):1396-1402.

17. Guo Y-X, Wang Z-N, Li Y-T, , et al. High-frequency oscillatory ventilation is an effective treatment for severe pediatric acute respiratory distress syndrome with refractory hypoxemia. Ther Clin Risk Manag 2016;12:1563-1571. https://doi.org/10.2147/TCRM.S115884

18. Arnold JH, Hanson JH, Toro-Figuero LO, Gutiérrez J, Berens RJ, Anglin DL. Prospective, randomised comparison of high-frequency oscillatory ventilation and conventional mechanical ventilation in pediatric respiratory failure. Crit Care Med 1994;22(10):1530-1539.

19. Wang C-C, Wu W-L, Wu E-T, Chou H-C, Lu FL. High-frequency oscillatory ventilation in children: Experience of a medical centre in Taiwan. J Formos Med Assoc 2008;107(4):311-315.

20. Brincat E, Cooke A, Butt W, Namachivayam SP. Long-term survival for children with acute 2016;42(11):1820-1821. https://doi.org/10.1007/s00134-016-4515-0

21. Brower RG, Lanken PN, MacIntyre N, et al. Higher versus lower positive end-expiratory pressures in patients with the acute respiratory distress syndrome. N Engl J Med 2004; 22;351(4):327-336.
22. Arnold $\mathrm{JH}$, Anas NG, Luckett $\mathrm{P}$, et al. High-frequency oscillatory ventilation in paediatric respiratory failure: A multicentre experience. Crit Care Med 2000;28(12):7.

23. Yehya N, Servaes $S$, Thomas NJ. Characterising degree of lung injury in paediatric acute respiratory distress syndrome. Crit Care Med 2015;43(5):937-946. https://doi.org/10.1097/ CCM.0000000000000867

24. Samransamruajkit R, Prapphal N, Deerojanawong J, et al. A comparison of clinical efficacy between high-frequency oscillatory ventilation and conventional ventilation with lung volume recruitment in pediatric acute respiratory distress syndrome: A randomised controlled trial. Indian J Crit Care Med 2016;20(2):72-77. https://doi.org/10.4103/0972-5229.175940

25. De Jager P, Kamp T, Dijkstra SK, et al. Feasibility of an alternative, physiologic, individualised open-lung approach to high-frequency oscillatory ventilation in children. Ann Intensive Care 2019:9(1):9. https://doi.org/10.1186/s13613-019-0492-0

Accepted 31 August 2019. 